\title{
Determination of dioecy in Hippophae salicifolia by evaluating gallic acid content through a validated HPTLC method
}

\author{
Ishita A. Basera ${ }^{1}$, Preeti D. Verma ${ }^{1}$ (D), Vijay P. Bhatt ${ }^{2}$, Mamta B. Shah ${ }^{1 *}$ (D) \\ ${ }^{1}$ Department of Pharmacognosy, L. M. College of Pharmacy, Gujarat, India. \\ ${ }^{2}$ Department of Botany, Herbal Research and Development Institute, Uttarakhand, India.
}

\begin{tabular}{l}
\hline ARTICLE INFO \\
\hline Received on: $28 / 06 / 2021$ \\
Accepted on: $27 / 12 / 2021$ \\
Available Online: $05 / 03 / 2022$
\end{tabular}

Key words:

Dioecy, gallic acid, HPTLC, Hippophae salicifolia, validation.

\begin{abstract}
Hippophae salicifolia D. Don, belonging to Elaeagnaceae family, exhibits dioecy and is extensively used for multipurpose due to its medicinal and nutraceutical potential. Although several research works have been carried out on the plant, no information is available regarding the impact of its dioecious nature on its phytochemicals and subsequent pharmacological properties. The present study is aimed at development of a high performance thin layer chromatography (HPTLC) method that is specific and reliable for the estimation of a marker compound gallic acid in both female and male counterparts of this dioecious plant, thus evaluating gender impact on chemical profile of the plant. For each sample, an ethyl acetate fraction of the hydrolyzed hydroalcoholic extract of $\mathrm{H}$. salicifolia was

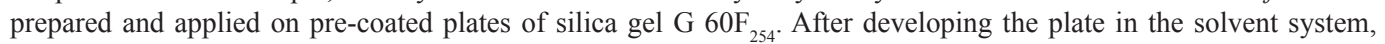
toluene:ethyl acetate:formic acid $(5: 4: 1, \mathrm{v} / \mathrm{v} / \mathrm{v})$, the identification and estimation was carried out by densitometric scanning at $270 \mathrm{~nm}$. The presence of gallic acid was confirmed by UV overlay of the spot resolving in test tracks with that of reference standard. The results suggested quantitative variation of the marker compound in female and male plants, indicating a clear gender bias. The proposed validated HPTLC method is simple, yet specific and accurate and would contribute to the quality assessment of $H$. salicifolia.
\end{abstract}

\section{INTRODUCTION}

Dioecy is a characteristic feature of species, implying that it has distinct staminate (male) and pistillate (female) flowers on separate plants (Bawa, 1980; Montalvao et al., 2021). It is associated with high diversity rates in morphological and anatomical characteristics of flowering plants (Rabska et al., 2021). Many medicinal plant species are apparently dioecious and quite a few researchers have studied the implications of dioecy (gender impacts) on active phytoconstituents and pharmacological actions of the dioecious medicinal plants, to find out the best gender possessing the optimum therapeutic value (Bajpai et al., 2012; Choudhry et al., 2014; Retuerto et al., 2009). Hippophae salicifolia D. Don, belonging to Elaeagnaceae family, is popularly called as "seabuckthorn." It is a deciduous shrub, occurring in the

\section{*Corresponding Author}

Mamta B. Shah, Department of Pharmacognosy, L. M. College of Pharmacy, Gujarat, India.E-mail: mbshah2007@ rediffmail.com icy heights of Himalayan region of India. As per the traditional systems of medicine, the plant shows beneficial effects in asthma, impaired lung conditions, cough, cold, sore throat, stomachache, and also possess wound healing properties (Arimboor et al., 2006a; Garbyal et al., 2005; Man and Dutt, 2008). Seabuckthorn species are extensively used for the treatment of diverse ailments that include gastric ulcers, coronary heart diseases, diarrhea, and also as antioxidant and immunomodulator (Arimboor et al., 2006a; Eccleston et al., 2002; Geetha et al., 2002; Xing et al., 2002). Hippophae salicifolia leaf extract is known to enhance the antioxidant defense against reactive oxygen species produced under hyperglycemic conditions, and thus helps in modulation of diabetes mellitus (Middha et al., 2019). Hippophae salicifolia is also reported to have anti-inflammatory, anticancer, antiatherosclerosis, and anti-sterility activities that are attributed to the presence of multivitamins and flavonoids in the aerial parts of this plant (Chakraborty et al., 2015; Dubey et al., 2018; Gupta et al., 2011; Mousmi and Handique, 2013). In addition, its fruits are utilized to improve appetite and as an antidote for food poisoning. 
They are useful in the paralysis of throat muscles and tongue, in lung complaints, influenza and catarrhal issues of airway (Negi et al., 1993; Uniyal, 1990). Seabuckthorn seed oil extracted from the berries possess significant nutritional and antimicrobial properties. It stimulates regenerative processes in the skin epidermis, reduces scars, and also causes healing of wounds. Due to its high content of linolenic acid and vitamin $\mathrm{E}$ along with its good antimicrobial property, seed oil is utilized in pharmaceutical, nutraceutical and cosmetic preparations (Moges et al., 2021; Zielinska and Nowak, 2017).

This plant is also found to be rich in vitamin $\mathrm{A}, \mathrm{B}_{1}, \mathrm{~B}_{12}$, $\mathrm{C}$, and $\mathrm{K}$; flavonoids like isorhamnetin, quercetin, myricetin, and kaempferol and carotenoids like lycopene, $\beta$-carotene, $\delta$-carotene, neoxanthin, violaxanthin, cryptoxanthin, and flavoxanthin (Arimboor et al., 2006a, 2006b; Kapoor et al., 1972; Lu, 1992). The vitamin $C$ content of fresh fruits of $H$. salicifolia is reported to be much higher $(224 \mathrm{mg} / 100 \mathrm{~g})$ than the other species under the Hippophae genus (Dinca et al., 2018). The phenolic contents identified in other species like Hippophae rhamnoides include $p$-hydroxybenzoic acid, gallic acid, protocatechuic acid, $p$-coumaric acid, vanillic acid, cinnamic acid, caffeic acid, and ferulic acid. Among the phenolics, gallic acid was found to be occurring in $\mathrm{H}$. salicifolia as a major constituent (Arimboor et al., 2008; Maheshwari et al., 2011; Sharma et al., 2008). Furthermore, gallic acid is a potent antioxidant phytoconstituent and is used as a reference standard in the estimation of phenolics and ascorbic acid. Hence, gallic acid can be considered as a biomarker compound for the qualitative as well as quantitative assessment of $H$. salicifolia.

A comprehensive literature survey revealed that some methods are available for the analysis of gallic in other plant samples, that include liquid chromatography methods, capillary electrophoresis methods, capillary gas chromatography method hyphenated with mass spectrometry and liquid chromatography combined with tandem mass spectrometry (Deodhar et al., 2012; Deshmukh and Prabhu, 2011; Kuskoski et al., 2012; Wang et al., 2013; Yue et al., 2006). But, no simple and validated high performance thin layer chromatography (HPTLC) method was reported for gallic acid estimation in $H$. salicifolia. Moreover, since $H$. saliciolia is an important medicinal dioecious plant, the characterization of gender-specific differences on its active constituents is essential. Unfortunately, no such systematic study has been done on this plant so far. Hence, the objective of the present study was to establish a new, simple, specific and accurate method for gallic acid quantification in the female and male plants of $H$. salicifolia, thereby also emphasizing implications of its dioecious nature on its chemical profile.

\section{MATERIALS AND METHOD}

\section{Plant material}

As $H$. salicifolia is a dioecious plant, fresh aerial parts of four samples were procured, including both female and male plants from two different provinces of Uttarakhand (India), i.e., Byans valley and Niti valley, in October month. The plant samples were authenticated by Dr. V. P. Bhatt, Taxonomist, Department of Botany, Herbal Research and Development Institute, Chamoli,
Uttarakhand, India. Voucher specimens (PAH/23082015/0104) have been deposited in Department of Pharmacognosy and Phytochemistry, L. M. College of Pharmacy, Ahmedabad. The fresh aerial parts were cut, dried properly, powdered, and passed through $80 \#$ sieve. The powdered samples were stored separately at room temperature in airtight containers.

\section{Chemicals and solvents}

Ethyl acetate, petroleum ether $\left(60^{\circ} \mathrm{C}-80^{\circ} \mathrm{C}\right), 5 \mathrm{~N}$ sulphuric acid, toluene, methanol, formic acid, and acetic acid of analytical grade (E. Merck, Mumbai, India) were used. Standard gallic acid (purity 99.9\%) was procured from Sigma-Aldrich Chemicals (India).

\section{Extraction and fractionation of plant material}

Accurately weighed $200 \mathrm{~g}$ of plant powders of the four samples were separately extracted successively with petroleum ether (thrice, $50 \mathrm{ml}$ ) and then ethyl acetate (thrice, $50 \mathrm{ml}$ ) by hot percolation method. The subsequent ethyl acetate fractions were hydrolyzed with $50 \mathrm{ml}$ of $5 \mathrm{~N}$ sulphuric acid and $20 \mathrm{ml}$ of toluene under reflux condition for 5 hours. The hydrolyzed extracts were further fractionated with ethyl acetate (thrice, $20 \mathrm{ml}$ ) and the obtained fractions of ethyl acetate were pooled along with the toluene fractions of the hydrolyzed extracts. The pooled fractions were further concentrated under vacuum to dryness to yield semisolid extracts. $10 \mathrm{mg}$ of these extracts were first dissolved in 5 $\mathrm{ml}$ methanol and then further diluted up to $10 \mathrm{ml}$ to yield test extracts of $H$. salicifolia. $15 \mu \mathrm{l}$ of test extracts were used for the chromatographic analysis.

\section{Optimization of the chromatographic method}

The test extracts were applied to pre-coated TLC plates at the preliminary stage of method development. Mobile phases, consisting of binary mixtures of solvents, toluene and ethyl acetate, were tested on the basis of polarity. Different proportions of toluene $(90 \%$ to $50 \%)$ and ethyl acetate $(10 \%$ to $40 \%)$ in a mixture were tried. As there was non-satisfactory separation of constituents, different combinations were tried with acetic acid and formic acid which showed that addition of formic acid gave best resolution of the individual constituents as evident from the fingerprint. Then, separation of different samples of $H$. salicifolia was performed on pre-coated HPTLC plates of silica gel $\mathrm{G} 60 \mathrm{~F}_{254}$ using the mobile phase, toluene:ethyl acetate:formic acid $(5: 4: 1, \mathrm{v} / \mathrm{v} / \mathrm{v})$.

\section{HPTLC analysis}

$5 \mathrm{mg}$ of standard gallic acid was dissolved in $25 \mathrm{ml}$ of methanol to obtain standard stock solution (200 ng/ $\mu \mathrm{l})$. Graded concentrations of the standard solution $(1-5 \mu 1)$ were applied on pre-coated TLC plates in the form of bands for calibration purpose.

The HPTLC analysis was carried out on $10 \times 10$ $\mathrm{cm}$ pre-coated HPTLC plates of silica gel G $60 \mathrm{~F}_{254}$ (E. Merck, Germany). The test extracts were applied to the plate along with the standard solution as $8 \mathrm{~mm}$ wide bands (12 $\mathrm{mm}$ apart) using CAMAG Linomat-V applicator (Muttenz, Switzerland) with the application speed of 6 seconds $/ \mathrm{ml}$. The plate was developed up to $8 \mathrm{~cm}$ distance in the mobile phase composed of toluene:ethyl 
acetate:formic acid $(5: 4: 1, \mathrm{v} / \mathrm{v} / \mathrm{v})$ in pre-saturated CAMAG twintrough chamber $(20 \times 10 \mathrm{~cm})$. The plate was dried in air for 5 minutes after development and scanned immediately at $270 \mathrm{~nm}$ using a deuterium lamp in CAMAG Scanner-3 (with WinCATS 5 integration software). The photo-documentation of the plate was done using CAMAG Reprostar-3 TLC visualizer. The calibration curve for gallic acid was prepared by plotting the peak area against the concentration of gallic acid and the concentrations of test samples were determined from the calibration curve.

\section{Method validation}

Validation of the developed method was carried as per ICH guidelines (ICH, 2005), by determination of linearity, precision (interday and intraday), specificity, accuracy, repeatability, limit of quantification (LOQ), and limit of detection (LOD). The linear response was determined by analyzing gallic acid calibration curve in the range of 200 to $1,000 \mathrm{ng} / \mathrm{spot}$ concentration and then applying linear regression analysis. The intraday precision was determined by analyzing standard gallic acid (200, 400, and $800 \mathrm{ng} / \mathrm{spot}$ ) for three times on the same day, while the interday precision was determined by analyzing the same spot for three consecutive days. Repeatability of peak area measurement was performed by measurement of the same spot for seven times. Seven times application of the same volume of standard solution was done and then peak area was measured for determining the repeatability of sample application. Specificity was determined by analyzing the sample solution for interferences from other constituents present in the $H$. salicifolia extracts. The peak purity of the marker compound was analyzed by comparing the overlay absorption spectra scanned at $270 \mathrm{~nm}$. Accuracy was confirmed at three different levels $(50 \%, 100 \%$, and $150 \%$ of working concentration). LOQ and LOD were determined at signal-to-noise ratio of $10: 1$ and $3: 1$, respectively.

\section{RESULTS AND DISCUSSION}

The literature survey concerning the biological potentiality and phytochemical profile underpin that evaluation of gender-specific variation concerning phytoconstituents and biological efficacy of $H$. Salicifolia has remained unexplored. Hence, this present study is tailored to evaluate gender-specific variation in the phytoconstituents. Hydrolyzed ethyl acetate extract yields of different samples of $H$. Salicifolia, i.e., Male Byans Valley (MB), Female Byans Valley (FB), Male Niti Valley (MN), and Female Niti Valley (FN) were found to be $12.5 \%, 11.8 \%, 11.2 \%$, and $12.4 \%(\mathrm{w} / \mathrm{w})$, respectively. The TLC fingerprint of test extract of each sample, using toluene:ethyl acetate:formic acid (5:4:1, $\mathrm{v} / \mathrm{v} / \mathrm{v}$ ) as the mobile phase, showed good separation of bands and revealed the presence of gallic acid as navy blue colored spot in daylight at $R_{\mathrm{F}} 0.42$, after derivatization by ferric chloride reagent.

In the HPTLC analysis, the peaks resolving at $R_{\mathrm{F}} 0.42$ in test solutions superimposed with that of gallic acid standard. The HPTLC fingerprint and the densitometric chromatogram of test extracts of all four samples is shown in Figure 1. The study of UV overlay absorption spectra obtained from the reference standard and the respective peaks from test indicated peak purity and specificity of the developed method (Fig. 1). The method was also accurate as indicated by the results of recovery studies. The calibration plot indicated that the peak area response was in linear association with standard gallic acid concentration in the range of 200 to $1,000 \mathrm{ng}$. The data of linearity, precision, repeatability, LOQ, LOD, specificity, and accuracy are given in Table 1. The amount of gallic acid in different test samples was found to be $0.426 \%, 0.718 \%, 0.143 \%$, and $0.566 \%(\mathrm{w} / \mathrm{w})$ in $\mathrm{MB}, \mathrm{FB}, \mathrm{MN}$, and FN samples of $H$. salicifolia, respectively.

In the present investigation, gallic acid was estimated as a marker compound by HPTLC method for the first time in both female and male plants of $H$. salicifolia procured from two different provinces of Uttarakhand, namely, Byans valley and Niti valley. The content of gallic acid was found to vary from $0.143 \%$ to $0.718 \% \mathrm{w} / \mathrm{w}$ in different samples, the highest amount being found in the aerial parts of female plants procured from Byans valley (FB) and the lowest in male plants of Niti valley $(\mathrm{MN})$. It was also observed that the amount of gallic acid was marginally higher in the female plants than their respective male plants. Thus, in line with the earlier observations (Cornago et al., 2011; Simpson, 2013), our experimental results also showed a significant correlation between the phenolic content and dioecy which is lacking in earlier findings. The HPTLC fingerprints of all the samples also revealed more number of bands in female plant extracts showing abundance of phytoconstituents as compared to

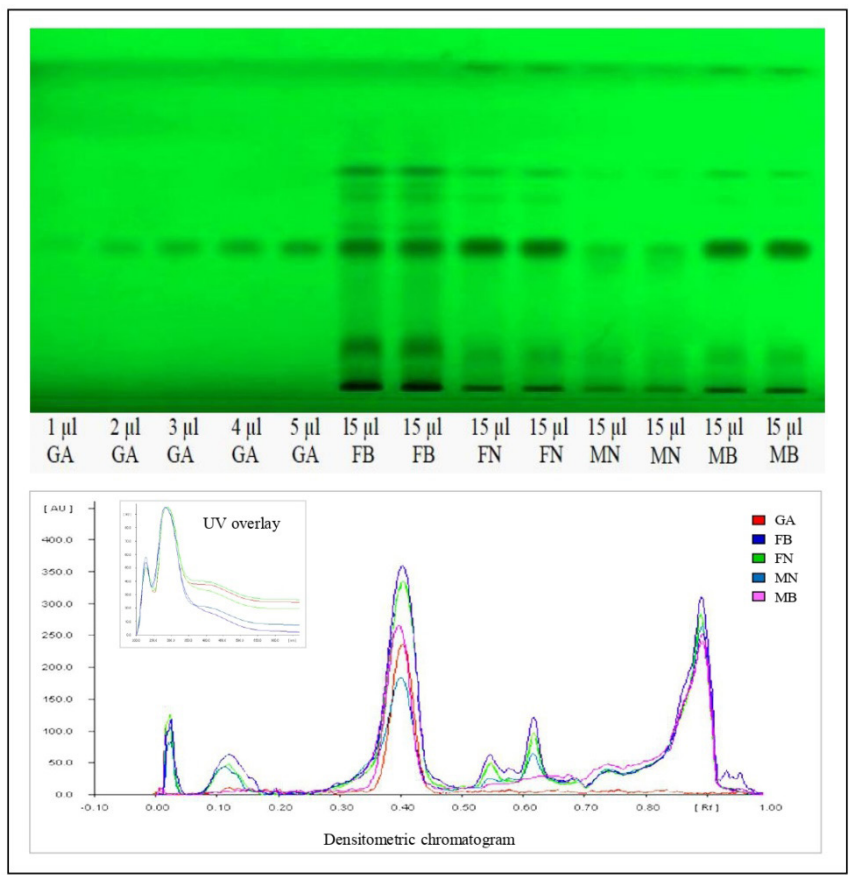

Figure 1. HPTLC plate and densitometric chromatogram of standard gallic acid with test extracts. GA, gallic acid standard; FB, female byans valley; FN, female niti valley; MN, male niti valley; MB, male byans valley. 
Table 1. Results of linearity $(n=6)$ and method validation parameters.

\begin{tabular}{cc}
\hline Parameter & Result \\
\hline Linearity range & $200-1,000 \mathrm{ng} / \mathrm{spot}$ \\
Regression equation & $y=11.49 \mathrm{x}-999.7$ \\
Correlation coefficient $\left(R^{2}\right)$ & 0.991 \\
Intraday precision & $0.31 \%-0.72 \% \mathrm{RSD}$ \\
Interday precision & $0.32 \%-0.88 \% \mathrm{RSD}$ \\
Repeatability of peak area measurement & $0.072 \% \mathrm{RSD}$ \\
Repeatability of sample application & $0.213 \% \mathrm{RSD}$ \\
LOD & $1.891 \mathrm{ng} / \mathrm{spot}$ \\
LOQ & $5.731 \mathrm{ng} / \mathrm{spot}$ \\
Accuracy & $97.56 \%-99.40 \%$ \\
Specificity & Specific \\
\hline
\end{tabular}

their male counterparts. Hence, the study indicated clear gender bias as well as influence of geographical differences on this plant.

\section{CONCLUSION}

The validated analytical method was developed with optimized chromatographic conditions for estimation of gallic acid as a marker compound in aerial parts of both female and male plants of $H$. salicifolia. The developed method is sensitive, precise, reliable, and specific as indicated by the results of validation parameters and has significant potential to indicate gender impact on this plant based on their chemical profile. Thus, the proposed validated HPTLC method would enable easy, yet accurate and specific analysis of gallic acid in the aerial parts of both genders of this plant and can be applied for the routine qualitative and quantitative assessment of $H$. salicifolia plants.

\section{ACKNOWLEDGMENT}

The authors would like to thank L. M. College of Pharmacy, Ahmedabad for providing necessary facilities for the conduction of this study.

\section{AUTHOR CONTRIBUTIONS}

All authors made substantial contributions to conception and design, acquisition of data, or analysis and interpretation of data; took part in drafting the article or revising it critically for important intellectual content; agreed to submit to the current journal; gave final approval of the version to be published; and agree to be accountable for all aspects of the work. All the authors are eligible to be an author as per the international committee of medical journal editors (ICMJE) requirements/guidelines.

\section{FUNDING}

There is no funding to report.

\section{CONFLICT OF INTEREST}

The authors declare that there are no conflicts of interest.

\section{ETHICAL APPROVALS}

This study does not involve experiments on animals or human subjects.

\section{DATA AVAILABILITY}

All data generated and analyzed are included within this research article.

\section{PUBLISHER'S NOTE}

This journal remains neutral with regard to jurisdictional claims in published institutional affiliation.

\section{REFERENCES}

Arimboor R, Kumar KS, Arumughan C. Simultaneous estimation of phenolic acids in sea buckthorn (Hippophae rhamnoides) using RPHPLC with DAD. J Pharmaceut Biomed Anal, 2008; 47(1):31-8.

Arimboor R, Kumar KS, Venugopalan VV, Arumughan C, Sawhney RC, Singh V. Fatty acids, tocols and carotenoids in pulp oil of three sea buckthorn species (Hippophae rhamnoides, H. salicifolia, and H. tibetana) grown in the Indian Himalayas. J Am Oil Chem Soc, 2006a; 83(4):359-64.

Arimboor R, Venugopalan VV, Sarinkumar K, Arumughan C, Sawhney RC. Integrated processing of fresh Indian sea buckthorn (Hippophae rhamnoides) berries and chemical evaluation of products. J Sci Food Agric, 2006b; 86(4):2345-53.

Bajpai V, Pandey R, Negi MP, Bindu KH, Kumar N, Kumar B. Characteristic differences in metabolite profile in male and female plants of dioecious Piper betle L. J Biosci, 2012; 37(6):1061-6.

Bawa KS. Evolution of dioecy in flowering plants. Ann Rev Ecol Systemat, 1980; 11:15-39.

Chakraborty M, Karmakar I, Haldar S, Nepal A, Haldar PK. Anticancer and antioxidant activity of methanol extract of Hippophae salicifolia in EAC induced swiss albino mice. Int J Pharm Pharma Sci 2015; 7(8):1-5

Choudhry N, Singh S, Siddiqui MB, Khatoon S. Impact of seasons and dioecy on therapeutic phytoconstituents of Tinospora cordifolia, a rasayana drug. BioMed Res Internat, 2014:1-11.

Cornago DF, Rumbaoa RGO, Geronimo IM. Philippine Yam (Dioscorea spp.) tubers phenolic content and antioxidant capacity. Philippine J Sci, 2011; 140(2):145-52.

Deodhar P, Kumar N, Gunesh G, Mukkanti K, Chandra S. Simultaneous determination of gallic acid and glycyrrhizic acid by reverse phase HPLC in herbal formulation. J Pharmaceut Res, 2012; 5(5):2867-9.

Deshmukh H, Prabhu PJ. Development of RP-HPLC method for qualitative analysis of active ingredient (gallic acid) from stem bark of Dendrophthoe falcate Linn. Int J Pharm Sci Drug Res, 2011; 3(2):146-9.

Dinca L, Holonec L, Socaciu C, Dinulica F, Constandache C, Blaga T, Peticila A. Hippophae salicifolia D. Don: a miraculous species less known in Europe. Not Bot Horti Agrobo, 2018; 46:474-83.

Dubey S, Ramana MV, Mishra A, Gupta PS, Awasthi H Seabuckthorn (Hippophae rhamnoides and Hippophae salicifolia) seed oil in combating inflammation: a mechanistic approach. Pharm Res, 2018; $10: 404-7$

Eccleston C, Baoru Y, Tahvonen R, Kallio H, Rimbach GH, Minihane AM. Effects of an antioxidant-rich juice (sea buckthorn) on risk factors for coronary heart disease in humans. J Nutr Biochem, 2002; 13(6):346-54

Garbyal SS, Aggarwal KK, Babu CR. Traditionally used medicinal plants in Dharchula Himalayas of Pithoragarh district, Uttaranchal. Indian J Trad Knowl, 2005; 4(2):199-207.

Geetha S, Sairam M, Singh V, Ilavazhagan G, Sawhney RC. Antioxidant and immunomodulatory properties of seabuckthorn (Hippophae rhamnoides) - an in vitro study. J Ethnopharmacol, 2002; 79(3):373-8.

Gupta SM, Gupta AK, Ahmad Z, Kumar A. Antibacterial and antifungal activity in leaf, seed extract and seed oil of sea buckthorn (Hippophae salicifolia D. Don) plant. J Plant Pathol Microbiol, 2011; 2(2):1-4.

ICH. Q2 (R1) International Conference on Harmonisation of Technical Requirements for Registration of Pharmaceuticals for Human Use. ICH, Geneva, Switzerland, 2005. 
Kapoor LD, Srivastava SN, Singh A, Kapoor SL, Shah NC. Survey of Indian plants for saponins, alkaloids and flavonoids III. Lloyd, $1972 ; 35: 288-95$

Kuskoski EM, Rios JJ, Bueno, JM, Fett R, Troncoso AM, Asuero AG. Capillary gas chromatography-mass spectrometry (CGC-MS) analysis and antioxidant activities of phenolic and components of Guarana and derivatives. Open Anal Chem J, 2012; 6:1-8.

Lu R. Sea buckthorn: a multipurpose plant species for fragile mountains. International Centre for Integrated Mountain Development (ICIMOD) publications' unit, Kathmandu, Nepal, 1992.

Maheshwari DT, Yogendra K, Verma MS, Singh SK, Singh VK. Antioxidant and hepatoprotective activities of phenolic rich fraction of sea buckthorn (Hippophae rhamnoides L.) leaves. Food Chem Toxicol, 2011; 49(9):2422-8.

Man V, Dutt B. Ethnobotanical studies in Sangla valley, district Kinnaur in Himachal Himalayas. J Econ Taxon Bot, 2008; 32:58-64.

Middha SK, Usha T, Basistha BC, Goyal AK. Amelioration of antioxidant potential, toxicity, and antihyperglycemic activity of Hippophae salicifolia D. Don leaf extracts in alloxan-induced diabetic rats. Biotech, 2019; 9:308.

Moges A, Barik CR, Purohit S, Gout VV. Dietary and bioactive properties of the berries and leaves from the underutilized Hippophae salicifolia D. Don grown in Northeast India. Food Sci Biotechnol, 2021; 30:1555-69.

Montalvao APL, Kersten B, Fladung M, Muller NA. The diversity and dynamics of sex determination in dioecious plants. Front Plant Sci, 2021; 11:580488.

Mousmi S, Handique PJ. Antioxidant and antibacterial activity of leaf, bark, pulp and seed extracts of sea buckthorn (Hippophae salicifolia D. Don) of Sikkim Himalayas. J Med Plants Res, 2013; 7(19):1330-8.

Negi KS, Tiwari JK, Gaur RD, Pant KC. Notes on ethnobotany of five districts of Garhwal Himalaya, Uttar Pradesh, India. Ethnobot, 1993; 5(1):73-81.

Rabska M, Warwick NWM, Iszkuło G, Gross CL. Intersexual differences in leaf size and shape in dioecious Adriana tomentosa. J Plant Ecol, 2021; 14:67-83.

Retuerto R, Lema BF, Roiloa SR, Obeso, JR. Gender, light and water effects in carbon isotope discrimination and growth rates in the dioecious tree Ilex aquifolium. Func Ecol, 2000; 14:529-37.
Sharma UK, Sharma K, Sharma N, Sharma A, Singh HP, Sinha AK. Microwave-assisted efficient extraction of different parts of Hippophae rhamnoides for the comparative evaluation of antioxidant activity and quantification of its phenolic constituents by reverse phase high performance liquid chromatography (RP-HPLC). J Agr Food Chem, 2008; 56(2):374-9.

Simpson BS. Dioecy in plants - is it an important factor for phytochemists to consider? Planta Med, 2013; 79(08): 613-5.

Uniyal MR. Utility of hitherto unknown medicinal plants traditionally used in Ladakh. J Res Educ Indian Med, 1990; 9(2):89-95.

Wang L, Halquist MS, Sweet DH. Simultaneous determination of gallic acid and gentisic acid in organic anion transporter expressing cells by liquid chromatography-tandem mass spectrometry. J Chromatogr B, 2013; 937:91-6.

Xing J, Yang B, Dong Y, Wang B, Wang J, Kallio H. Effects of sea buckthorn (Hippophae rhamnoides L.) seed and pulp oils on experimental models of gastric ulcer in rats. Fitoterapia, 2002; 73(7):644-50.

Yue ME, Jiang TF, Shi YP. Determination of gallic acid and salidroside in rhodiola and its preparation by capillary electrophoresis. $\mathrm{J}$ Anal Chem, 2006; 61:365-8.

Zielinska A, Nowak I. Abundance of active ingredients in seabuckthorn oil. Lipids Health Dis, 2017; 16:95.

How to cite this article:

Basera IA, Verma PD, Bhatt VP, Shah MB. Determination of dioecy in Hippophae salicifolia by evaluating gallic acid content through a validated HPTLC method. J Appl Pharm Sci, 2022; 12(03):082-086. 